\title{
Formación de especialistas médicos en Chile
}

\author{
Formation of medical specialists in Chile
}

En el sistema público de salud hay un déficit de 1.700 jornadas de médicos especialistas, entre ellos cirujanos y anestesistas, según lo que consignó en 2010 un estudio realizado por el Banco Mundial y el Ministerio de Salud. El problema tiene múltiples causas, entre las que se cuentan que el país carece del número suficiente de especialistas según población, aunque tiene una tasa adecuada de médicos generales; el autofinanciamiento de los programas de formación; y la ausencia de una política de recursos humanos que retenga a los especialistas en el sistema público de salud, entre muchos otras.

Sin embargo, estamos avanzando. Desde que se inició un trabajo en que han participado los actores más relevantes en el tema, entre ellos el Colegio Médico de Chile, la Asociación de Facultades de Medicina de Chile (ASOFAMECH) y el mismo Ministerio de Salud, el Estado ha aumentado el financiamiento para becas de especialización. Es asi que hoy un $80 \%$ de las becas que ofrecen las casas de estudios superiores del país son financiadas por el Estado.

Cabe destacar que el número de especialistas financiados por el Ministerio de Salud ha ido aumentando sustantivamente desde el año 2008, con un cupo de un poco más de 500 en ese año hasta llegar a 755 nuevos becados en el año 2012. En base a los elementos del diagnóstico y a los lineamientos políticos de la Secretaría de Estado, se priorizó la formación en las siguientes especialidades: Anestesiología, Medicina Interna, Otorrinolaringología, Oftalmología, Traumatología y Ortopedia, Dermatología, Radiología y Cirugía General. En base a criterios demográficos se agregaron Geriatría, Medicina Intensiva y Medicina de Urgencia. Es así que se proyecta que en los próximos 5 años se podrá cerrar la brecha de las especialidades más críticas.

Pero esto no basta. Es fundamental establecer una política pública que retenga y mantenga los recursos humanos especializados en el sector público de salud. Esta política debe trascender al gobierno de turno $y$ debe tener prioridad presupuestaria y política. No es suficiente que el Ministerio de Salud haya doblado las exigencias a quienes realizan una beca, a fin de que cumplan efectivamente con el compromiso de este esfuerzo trabajando en el sistema público por el doble del número de años que requiere su formación. Se hace primordial que los médicos especialistas de experiencia y trayectoria puedan mantenerse en el sistema público, a fin de que puedan entregar su conocimiento y experiencia al $75 \%$ de la población que en él se atiende.

Las universidades, por nuestra parte, también hemos hecho esfuerzos. Hemos aumentado la oferta de cupos y programas de especialidad en un 20\% a nivel país. En el caso de la Universidad de Chile este incremento llega al 30\% en los últimos cinco años, y el $80 \%$ de nuestros cupos están siendo entregados al Ministerio de Salud, reservándonos algunos de ellos para la formación de nuestros cuadros académicos y la entrega de becas a los mejores egresados.

Sin embargo, el aumento de la oferta, por parte de las universidades, tampoco es suficiente. Debemos ir más allá, pues el desafio es la calidad. Chile debe formar especialistas de excelencia, bajo los estándares adecuados. Se hace relevante revisar los mecanismos de acreditación de los programas de especialidad, los cuales deben tener una masa crítica de docentes especialistas; planes de estudio actualizados y que permitan un sistema de seguimiento; una selección adecuada de los estudiantes, contemplando motivación y aptitudes, entre otros aspectos. Sin lugar a dudas, el país necesita un sistema de acreditación riguroso, con estándares objetivables y conocidos, incluyendo también información acerca del desempeño global de los especialistas que egresan de cada programa. Junto a todo lo anterior, la acreditación de las especialidades debería ser obligatoria.

Es crítico contar con muy buenos especialistas. De ello no sólo depende la salud y la vida de muchos chilenos por muchas generaciones -además de los éxitos sanitarios de Chile-, sino la confianza y las esperanzas de perfeccionamiento y calidad profesional de centenares de médicos del país.

Dra. Cecilia Sepúlveda C.

Decana Facultad de Medicina Universidad de Chile, Santiago, Chile. 